\title{
Small airways: a time to revisit?
}

\author{
David J Evans, Malcolm Green
}

The branching network of airways in the lung poses a complex challenge to both physiologists and physicians. Measurements of lung function have been made for nearly 200 years. Davy (1800) and Hutchinson (1844) were amongst the first to recognise and measure lung volumes. Despite these early discoveries, progress in understanding pulmonary physiology was intermittent. Rohrer (1925) and Rahn (1946) established the concepts of pressure and volume relationships in the lung and Rohrer alluded to the possibility of volume dependent airways resistance, although he did not live long enough to make these measurements himself. ${ }^{2}$ In fact, it was not until the 1960s that the issue of airways resistance was resolved and the distinction drawn between the large and small airways. ${ }^{34}$ Small airways are usually defined as those airways of less than $2 \mathrm{~mm}$ internal diameter and equate to generations 12-23 of Weibel's model of lung architecture. ${ }^{3}$ Although the small airways are themselves tiny, the dichotomously branching pattern of the tracheobronchial tree results in increasingly large numbers of airways in peripheral generations. This results in very low resistance of each generation of small airways, so that in total they contribute only about $10 \%$ of the total airway resistance of the tracheobronchial tree. ${ }^{56}$ Thus, most of the small airways can be damaged or destroyed before symptoms occur and before any of the conventional tests of lung function, in particular measurements of airway resistance, show loss of function. This led Mead to label the small airways as the "silent zone of the lung". 5

Physiological measurements of the small airways function include vital capacity (VC) and flow rates at low lung volume (MEF25\%). Diseases involving small airways may cause partial obstruction, but because of their size often lead to complete obliteration. For this reason the vital capacity can be reduced by dysfunction of the small airways and this measurement may be affected more than the forced expiratory volume in one second $\left(\mathrm{FEV}_{1}\right)$ or peak expiratory flow (PEF). Despite this, vital capacity is not specific and maximum expiratory flow rates at low lung volumes probably better reflect small airway function. However, these tests are technically harder to perform and show considerable variability as they are dependent on absolute lung volume, making results difficult to interpret. ${ }^{78} \mathrm{~A}$ paradoxical fall in forced expiratory ratios (FER; $\mathrm{FEV}_{1} / \mathrm{FVC}$ ) is sometimes seen in patients with small airways obstruction following effective treatment. This may indicate preferential opening of the small airways (FVC) relative to dilatation of the larger airways. ${ }^{9}$ In severe cases a reduction in gas transfer coefficient (TLCO) as well as hypoxia may be recognised, although these changes occur late in the disease and are non-specific. ${ }^{10}$

More sophisticated measurements of small airways function have been developed. Frequency dependent compliance, density dependent gas flow studies, and measurements of closing volumes offer more sensitive assessment and may allow earlier identification of small airways dysfunction. ${ }^{11}{ }^{12}$ However, these tests are complex (requiring operator expertise and subject aptitude) and are available only in research centres.

To compound the problem some respiratory conditions affect the lung in a patchy distribution, further weakening physiological measurements of whole lung function. Physi- ological changes associated with loss of small airway function may be obscured by coexisting lung restriction such as interstitial lung disease. ${ }^{13}$ As a result of these problems both routine and advanced lung function tests were found to be inadequate tools to quantify the pathophysiology of small airways diseases until it is widespread and well established. This may be one reason why there has been a loss of interest in the small airways. ${ }^{78}$

Recent evidence, however, suggests that identification of small airway dysfunction may indeed be important, not only for diagnosis but also for the management of various pulmonary disorders. Studies in asthma show evidence of increases in inner airway wall thickness and inflammation of small airways in mild to moderate disease. These changes are most striking in cases that progress to chronic asthma and in fatal attacks. ${ }^{14}$ It may be more important than hitherto appreciated to identify and treat inflammation at this level to prevent airway remodelling and progression to airway fibrosis and irreversible damage. ${ }^{15}$ In chronic obstructive pulmonary disease (COPD) recognition of accelerated and progressive loss of the small airways early in the disease would allow research into the development of effective new treatment regimens. To date, smoking cessation remains the only effective disease modifying option. Bronchiectasis, often assumed to be associated with large airway pathology alone, is now identified with pathology in the smaller airways, possibly at the earlier stages of the natural history, and this change may also underlie the pathophysiology of the process. ${ }^{16}$ Viruses, especially respiratory syncytial virus, may involve the small airways and infrequently lead to irreversible damage in the form of obliterative bronchiolitis. ${ }^{17}$ Other conditions where early diagnosis and treatment of small airways dysfunction may also be relevant include graft-versus-host-disease, ${ }^{18}$ lung rejection following transplantation, ${ }^{19}$ and in bronchiolitis associated with collagen vascular conditions. ${ }^{13}$

The diagnostic part of this challenge may become easier with the application of high resolution computed tomographic (HRCT) scanning. Modern HRCT scanning captures fine lung detail that can demonstrate morphological changes in the small airways associated with dysfunction too subtle to be identified on lung function testing alone. ${ }^{20}$ This contrasts with plain film radiography and other imaging techniques where the appearances may be normal or equivocal. The HRCT appearance of small airways disease comprises patchy areas of high and low attenuation of the lung parenchyma - so called "mosaic perfusion"-thought to be a consequence of reflex vasoconstriction in underventilated areas of the lung. This feature is characteristically accentuated on scans obtained at the end of expiration, consistent with gas trapping in the lung, and may distinguish the heterogeneity seen on inspiratory CT images from those mosaic patterns occasionally seen in thromboembolic or other vascular disease. ${ }^{21}$ Whilst patchy perfusion of the lung is seen as part of emphysema, this feature tends not to be emphasised using expiratory CT scanning. Other features include loss of the usual reduction in lung volume on expiration and subsegmental bronchial dilatation. ${ }^{21}$ Interpretation of the HRCT scan alongside measurement of KCO (reduced in emphysema but preserved in small airways disease) usually allows further discrimination. ${ }^{10}$ 
Increased awareness of the importance of diagnosis in small airways disease is the first step, but the therapeutic challenge is to reverse the damage or prevent progression at a stage when the pathological process may be reversible. Delivery of anti-inflammatory agents to the periphery of the lung may require improvement of aerosol or nebuliser technologies. The dose of inhaled steroid may not be as pertinent as their delivery profile down the tracheobronchial tree. ${ }^{22}$ There may be a subgroup of patients with asthma predominantly involving small airways in whom oral agents may be indicated, as the systemic route is likely to reach the large surface area of the small airways. ${ }^{23}$

Identification of individuals with small airways disease depends on the integration of HRCT scanning into management algorithms. Earlier diagnosis will allow more effective understanding of the role of the small airways in the pathogenesis of common lung conditions and a more rational approach to treatment that may ultimately alter the prognosis of these disabling conditions.

DAVID J EVANS

Royal Brompton Hospital, London SW3 6NP,

UK

1 Rohrer F. Handbook der monalen und pathologischen Physiologie, II 1925: 70-5. 2 Rahn H, Otis AB, Chadwick LE, et al. The pressure-volume diagram of the thorax and the lung. F Physiol 1946:146:161-78.

3 Weibel ER. Morphometry of the human lung. New York: Academic Press, 1963.

4 Green M. How big are the bronchioles? St Thomas's Hospital Gazette 1967; 63:136-9.
5 Macklem P. Mead J. Resistance of central and peripheral airways measured by a retrograde catheter. F Appl Physiol 1967;22:395-401.

6 Hogg JC, Macklem PT, Thurlbeck WM. Site and nature of airway obstruction in chronic obstructive lung disease. N Engl f Med 1968;268:1355-60.

7 Macklem PT. Obstruction in the small airways. Am f Med 1972;52:721-4.

8 Soloman D. Clinical significance of pulmonary function tests; are small airways tests helpful in the detection of early airflow obstruction? Chest 1978; 74:567-9.

9 Green M. The small airways. In: Besser GM, ed. Advanced medicine. Pitman Medical, 1977;13:278-88.

10 Turton CW, Williams G, Green M. Cryptogenic obliterative bronchiolitis in adults. Thorax 1981;36:805-10.

11 Woolcock AJ, Vincent NJ, Macklem PT. Frequency dependence of compliance as a test for obstruction in the small airways. $\mathcal{f}$ Clin Invest ;48:1097-105.

12 Gelb AF, Zamel N. Simplified diagnosis of small airway obstruction. N Engl f Med 1973;288:395-8.

13 Ostrow D, Cherniack RM. Resistance to airflow in patients with diffuse interstitial lung disease. Am Rev Respir Dis 1973;108:205-9.

14 Carroll N, Elliot J, Morten A, et al. The structure of large and small airways in nonfatal and fatal asthma. Am Rev Respir Dis 1993;147:405-10.

15 Park JW, Hong YK, Kim DK, et al. High resolution computed tomography in patients with bronchial asthma; correlation with clinical features, pulmonary functions and bronchial responsiveness. F Int Allergy Clin Immunol 1997;7:186-92.

16 Barker AF, Bardana EJ. Bronchiectasis: update of an orphan disease. Am Rev Respir Dis 1988;137:969-78.

17 Green M, Turton CW. Bronchiolitis and its manifestations. Eur $\mathcal{F}$ Respir Dis Green M, Turton CW. B
1982;Suppl 121:36-42.

18 Breuer R, Lossos IS, Berkmann N, et al. Pulmonary complications of bone marrow transplantation. Respir Med 1993;87:571-9.

19 Madden BP, Kamalvand K, Chan CM, et al. The medical management of patients with cystic fibrosis following heart-lung transplantation. Eur Respir f 1993;6:965-70.

20 Muller NL, Miller RR. Diseases of the bronchioles: CT and pathological findings. Radiology 1995;196:3-12.

21 Desai SR, Hansell DM. Small airways disease: expiratory computed tomography comes of age. Clin Radiol 1997;52:332-7.

22 Kamada AK, Szefler SJ, Martin RJ, et al. Issues in the use of inhaled glucocorticosteroids. Am f Respir Crit Care Med 1996;153:1739-48.

23 Evans DJ, Taylor DA, Zetterstrom O, et al. A comparison of low dose inhaled budesonide plus theophylline and high dose inhaled budesonide for patients with moderate asthma. N Engl f Med 1997;337:1412-18. 